\title{
Decision Support in Contract Formation for Commercial Electronic Services with International Connection
}

\author{
Martin Waldburger and Burkhard Stiller \\ University of Zürich, Communication Systems Group (CSG), Switzerland \\ \{waldburger, stiller\}aifi.uzh.ch
}

\begin{abstract}
This section addresses the automated and legally compliant determination of key contract parameters for commercially and internationally provided electronic services in the Internet. It designs and implements a decision support system that provides recommendations on suited contract parameters at the time of contract formation. Recommendations base on automated reasoning taking into consideration the relevant set of service- and contract-specific facts. The range of facts to be considered is imposed by the laws of these states that have sufficient connection with the international service contract to be concluded. Accordingly, this section develops and documents the solid basis for the decision support system, consisting of an information model that integrates perspectives of service and contract management as well as in a detailed method to formally model the legal basis for machine execution.
\end{abstract}

Keywords: Decision support, electronic service, Private International Law (PIL), contract, dispute resolution.

\section{Introduction and Motivation}

Electronic business in the Internet has become an important driver for economic growth. The provisioning of commercially offered electronic services in the Internet - e.g., content, news, or social networking services - requires the conclusion of an international contract in case the respective service is provided across borders. In international contracts, two contractual parameters are of key importance: jurisdiction and applicable law. Jurisdiction indicates which state's courts are authorized to hear and decide on a potential contract conflict [1], while applicable law indicates under which state's law a court decision shall be found [2].

The way jurisdiction and applicable law choices are made in international service contracts today is often not compliant with the relevant provisions of Private International Law (PIL). Jurisdiction and applicable law provisions are usually present in terms of choices made, but these choices may be illegitimate. Illegitimate choices are voided (and replaced by PIL-compliant terms) should a dispute arise and a contract claim be deposited in a court. Jurisdiction and applicable law provisions, thus, might have a considerable impact on the risk assessment of an international service contract to be concluded [3-5]. Given this risk and the imminent uncertainty outlined, service providers 
and customers alike need support in forming international service contracts [5, 4, 6, 7]. In particular, they need to know about jurisdiction and applicable law choices they can rely on so that these parameters may become part of an SLA (Service Level Agreement). To date, however, there is no alternative available to the static, PIL-ignorant way adopted currently. This lack is perceived as a major hurdle to foster adoption of (international) electronic business.

Hence, this section 1 is a pioneering effort to support service providers and service customers in international service contracting by means of a decision support system developed [8, 9]. This system produces a list of recommended jurisdictions and/or applicable laws during contract formation phase. Recommendations are determined in an automated and compliant manner according to the PIL-driven contract- and servicespecific set of connecting factors. Hence, it forms a dedicated task of Service Level Management (SLM).

This implies a number of challenges to be addressed, as there is considerable complexity in selecting the right PIL(s), modeling the accordingly relevant provisions, and implementing modeled laws in terms of a decision support system to produce jurisdiction and applicable law recommendations. In order to reflect and integrate different notions originating from different jurisdictions and their laws, a common information model basis is built. In the light of a method lacking to identify, select, and formally model the relevant legal basis, such a method is developed. In consideration of both, modeling method and information model, an implementation method is determined. Finally, an automated determination of jurisdiction recommendations is shown feasible and fully operational for the example of the main European PIL regulation modeled and implemented.

\section{Background Information and Related Work}

Given the inherent complexity of procedures in PIL the following gaps in concepts, models, and implementation have to be met:

- Information model, modeling method, and implementation: The analysis of stateof-the-art in those areas of scope considered has revealed that there are substantial gaps (a) in a common information model considering dimensions of service and contract management, (b) in a lacking method to identify, analyze, and formally model a PIL of interest, and (c) in a decision support system implementation helping contract parties by means of reliable recommendations on jurisdiction and applicable law. These three components (a) to (c), hence, constitute the key set of major contributions focused in this section.

- Applicable notion of service and contract: The modeling method, the implementation, and especially the information model shall consider and reflect concepts as well as concrete information artifacts in relation to the type of service (purely electronic services for monetary compensation) and contract (bilateral international service contract under PIL) assumed here. Moreover, the contract type of a service

\footnotetext{
${ }^{1}$ Thesis available at http://www.csg.uzh.ch/staff/waldburger/extern/ publications/Dissertation-Martin-Waldburger.pdf
} 
contract shall be investigated and characterized in detail. The comprehensive analysis and emulated contract qualification of a service contract as performed in a separate case study shall provide for a fourth major contribution of this section in addition to the information model, modeling method, and implementation.

- Consistency and compliance: In particular the modeling method, but also the information model and the implementation, shall consider and reflect characteristics of PIL procedures. This implies, for example, a time-wise back porting of disputedependent PIL provisions to the time of contract conclusion. Overall, legal compliance and content-wise consistency with a law to be modeled are key issues while interpretation, albeit not completely avoidable, shall be kept to a minimum.

- Extension of an existing information model: The information model provides the common set of information concepts and information artifacts for both, modeling method and implementation. The SLM information model as developed and documented in [10] qualifies as a well-suited, established basis for model extensions. Model adaptations are mainly needed to reflect both, service and contract management dimensions.

- Rule-based system: The implementation shall adopt a rule-based system-driven approach, as rule-based systems show advantages in building expert systems addressing decision-based procedures that are characterized by high complexity. Hence, with the help of a knowledge base, a modeling result consisting mainly of conditions and actions, and the inference engine, a decision support system as introduced and motivated shall be implemented in logic programming.

\section{Research Methodology}

Figure 1 outlines the overall approach developed within this section. The first step consists in identifying potentially affected jurisdictions by an international service contract to be concluded. This should happen in the same way a court dealing with a PIL-oriented claim would proceed. A court would collect basic connecting factors and determine on this basis jurisdictions with potential connection. In the contract conclusion case, such procedure is to be reflected by the contract parties to submit the respective set of contract party- or service-specific connecting factors of interest. A complete implementation takes these factors in consideration and produces a list of supposedly connected jurisdictions. For each jurisdiction identified, the set of relevant PIL sources is determined. Criteria for the PIL selection are related to application of a PIL in question, namely whether a law applies to a case in question (material application), whether it is in force for the time frame in question (temporal application), whether it applies in the location or locations touched (geographical application), and whether it supersedes other PILs or is subsidiary to another PIL (hierarchical application).

In step 2, each PIL identified needs to be reflected by a formal model (e.g., in terms of an activity diagram; one diagram per PIL), which is implemented in order to produce jurisdiction/applicable law-related output. Modeling, implementation, and output generation base on a common information model as well as a common modeling and implementation method. By every new PIL modeled, common parts might need to be altered in order to reflect so far non-covered aspects. Updates in the information model 


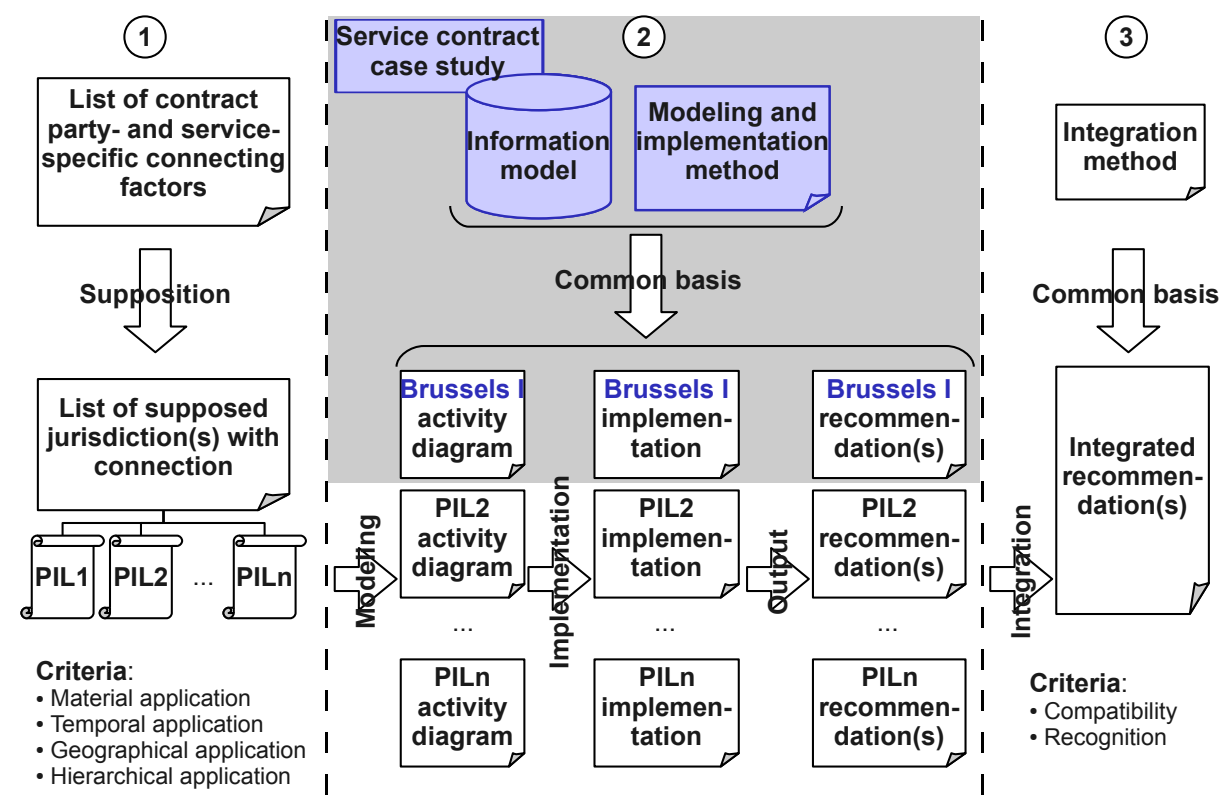

Fig. 1. Overall Three-step Approach and Focus Area (Gray Background)

and the method are expected to tend less frequent with the number of already modeled PILs. Moreover, changes in the underlying information model might provoke an update in the set of basic connecting factors to be collected during step 1. Connecting factors are of utter importance since if an important connecting factor is missing in the first place, a relevant jurisdiction (and related PILs) might not be investigated at all.

A list — one list per PIL considered — of recommended jurisdiction(s) and/or applicable law(s) is produced in step 2. These lists constitute the main outcome of this step. The procedure, however, cannot end here. Contract parties should obtain additional information with respect to compatibility of the different recommendations. Due to a territorial principle in law (state sovereignty) there is no mechanism in place, per se, that guarantees consistency (in terms of compatibility) within jurisdiction/applicable law provisions originating from different PILs. Only in cases where a single list of recommendations is produced - a case, however, which is rather unlikely as it is a very special case - or in case multiple lists are fully compatible (congruent lists) the mitigation strategy to adopt is clear.

The focus of this section is exclusively on the core of step 2, including several substeps ( $c f$. area with gray background in Figure 1). In particular, a thorough investigation of how to formally reflect a PIL leads to substantial methodological contributions. Methodology application is assessed for an example PIL modeled, the Brussels I [11] regulation. The detailed modeling method with respect to PIL identification, PIL selection, and law analysis is developed accordingly. Focus in this context is put on major cases meaning that the law analysis method includes aspects assumed to reflect typical circumstances while aspects such as reservations are not considered. The functional 
modeling method is completed by means of guidelines and criteria outlined for a successful PIL modeling.

In order to develop a comprehensive understanding of international service contracts, this section's fourth major contribution beyond information model, modeling method, and implementation, is found in an extensive case study to conduct a simulated contract characterization. The accordingly developed notion of an international service contract determines a key driver to shape a suited information model. The type of contract investigated is in relation to Bandwidth-on-Demand (BoD), while the contract qualification itself is simulated by means of nominate contract types of the Swiss code of obligations [12].

The investigation in a BoD product case is conducted by means of a real-world BoD product offering. The BoD product family looked at in detail is termed Ethernet Virtual Private Line (EVPL) [13] as offered by Verizon Business. This BoD product case embraces the Verizon EVPL-Metro and -National BoD offerings. More specifically, it includes the embracing study of the complete set of customer agreement components, covering service guides, terms and conditions, charge definitions, terminology definitions, and SLAs.

\subsection{Design Science Approach}

Figure 2 visualizes the research methodology in relation to modeling and implementation phases. The methodology follows a design science approach (as opposed to a behaviorist approach) [14] and is represented based on the method introduced by [15]. Accordingly, this section is mainly concerned with the design of artifacts and the contribution of scientific knowledge. In terms of the research object envisaged, a sociotechnical focus on international service contract-related, electronic business-related transactions is taken. In this context, action system and information system artifact development is envisioned. The first reflects the work flows interpreted from PIL procedures to determine jurisdiction and applicable law. The second reflects the actual implementation in terms of a system to enable an automated jurisdiction and applicable law recommendation determination for a service provider and a service customer at the time of contract formation.

In addition to action and information system artifacts, the key contribution in terms of knowledge contribution consists, on the one hand, in the underlying design artifact developments of the respective information and work flow models, on the other hand, in a conceptual framework how to identify, analyze, and model multiple PILs as well as related service types in a technically and legally correct, economically efficient, and scalable manner. The information model and work flow model find expression in a formal language, namely in UML2 Activity Diagrams and UML2 Class Diagrams (information model) as well as formally expressed rules. The modeling and implementation method, i.e., the applicable conceptual framework, finds expression in natural language.

The overall methodology bases on a central hypothesis and it follows a common purpose. The hypothesis adopted is driven by a service provider's and service customer's identified need for improved risk assessment along the complete contract and service life cycle with respect to international service contracting. The automated and legally compliant determination of jurisdiction and applicable law recommendations for 


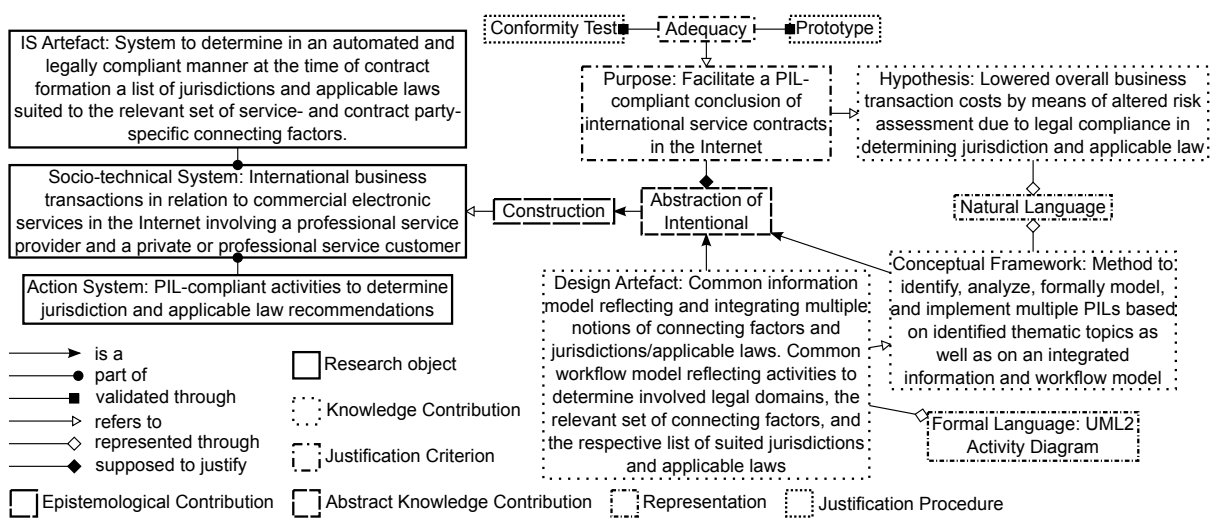

Fig. 2. Research Methodology

international service contracts shall reveal increased predictability and legal certainty for both contract parties.

\section{Achievements}

With the relevant purpose, hypothesis, and problem formulated, the set of claims have been translated into the key set of five specific objectives with respect to the design, implementation, and testing of a decision support system to produce jurisdiction and/or applicable law recommendations. Claims, objectives, and primarily the identified gaps have shaped the range of four major contributions as follows:

- International service contract case study: Based on a real-world, complex service contract construct assessed, a profound service and international service contract understanding has been obtained.

- Information model covering service and contract management: The understanding gained in the case study conducted has provided the solid basis for extending an established information model in SLM with the relevant perspective on contract management. In particular, information concepts and information artifacts have been determined to reflect characteristics of international service contracts.

- PIL modeling method: In order to ensure legal compliance and consistency with the relevant PIL basis an extensive method to identify, analyze, and formally model a PIL of interest has been developed. This method considers information concepts and artifacts of the information model determined. It results in a UML2 activity diagram representing a given PIL source.

- Decision support system producing recommendations: Driven by the outlined problem to be solved in this section, a service provider and a service customer need decision support when forming a service contract with international connection. To this aim, a previously modeled activity diagram is implemented as a rule-based system establishing a decision support system which produces recommendations on jurisdiction(s) and/or applicable law(s). 
In terms of gaps addressed, a detailed results valuation discussion has revealed that all four contributions have been fully and successfully achieved. Equally, all five gaps identified were found completely addressed.

\subsection{Claims and Objectives Addressed}

In consideration of those four major contributions achieved and the set of five gaps successfully addressed, four claims are assessed qualitatively as follows:

- Trust-building in international electronic business: Lack of trust in international electronic business is perceived as a major hurdle to wider adoption of commercial electronic service provisioning and to implement harmonized markets. Accordingly, this section aims to foster trust of service customers and service providers in international electronic business. The existence of additional information at the time of contract formation made available by the decision support system implemented is clearly rated as a trust-building measure. Additional information shows characteristics of recommendations. Without the decision support system, contract parties do not dispose of any information at all. In particular, they lack a notion of suited, i.e., recommendable jurisdiction(s) and applicable law(s) - recommendations that were determined according to the relevant legal basis, following a fully documented law modeling and implementation method.

- Increased legal certainty in international service contracting: The observed status quo in international service contracting bears considerable risks for both contract parties. With respect to dispute resolution means, this is mainly due to legal uncertainty in valuing risks of foreign jurisdiction and foreign law applied. None of the four major contributions achieved in this section is able to produce guaranteed legal certainty and to overcome the inherent design gap between the borderless infrastructure of the Internet and the territorial perspective of PIL. Nevertheless, this section reveals a path toward increased legal certainty, especially by the design and implementation of a decision support system which produces recommendations that both contract parties can rely on as they have been determined in accordance with PIL and based on a transparent method.

- Legal compliance in determining jurisdiction and applicable law: The production of a list of recommended jurisdiction(s) and applicable law(s) follows the procedures imposed by the respective PIL modeled and implemented directly. As long as the relevant set of PILs is modeled and implemented, the relevant set of recommendations may be obtained. Thus, legal compliance is provided, in principle. Alone, erroneously modeled provisions cannot be excluded completely. This is perceived less an issue of the PIL modeling method developed than an issue of how to correctly interpret running text in a law - laws do not constitute formal specifications. Hence, a certain degree of interpretation remains unavoidable.

- Risk assessment due to informed choices and PIL awareness: For producing a list of recommended jurisdiction(s) and applicable law(s), the respectively relevant connecting factors must be known. In case of Brussels I, the set of 12 connecting factors was required. In a productive decision support system, both contract parties would be required to submit a set of connecting factors initially. The fact alone that both 
contract parties would have to answer imperatively about a number of these factors implies a minimum degree of awareness that the contract to be concluded would have international connection (e.g., customer from a foreign state, provider from a foreign state). Given such minimum degree of awareness assumed, both contract parties are likely to realize that a potential dispute might bear certain risks - even if the actual detailed legal consequences may not be appreciable.

Such an approach fosters trust in international electronic business, increases legal certainty, determines recommendations in compliance with PIL, and allows for risk assessment due to informed choices and PIL awareness. Subsequently, the qualitative assessment of five objectives reads as follows:

- Automation support: The decision support system implemented allows for automated reasoning. It implements an activity diagram modeled for a given PIL as a rule-based system. Both, modeling method and decision support system implementation, envision an automated determination of jurisdiction and/or applicable law recommendations. Hence, automation support is provided, in principle. The way the decision support system prototype for Brussels I is implemented, however, relies on pre-determined input in terms of facts. Facts reflect connecting factors. In a productive decision support system, not only the reasoning, but also the acquisition of connecting factors from both contract parties would have to be implemented dynamically.

The decision support system implemented is found to produce results in terms of recommendations. It produces recommendations in accordance with the underlying modeled and implemented PIL procedures considered, and it implements activity diagrams which result from a modeling method that translates any ex post provision (focus on contract enforcement phase) to the respective ex ante provision (focus on contract formation phase).

- Integration of different national and supra-national PILs: All contributions made throughout this section are designed in a way to allow for flexibility in terms of general application and extension. This means that, even though an example service contract and an example PIL was used to concretize contributions at all levels, the service and contract notion obtained in the case study conducted is generic enough that the developed information model features information concepts of wide applicability. With respect to information artifacts, the information model currently foresees specific artifacts for Brussels I and Rome I [16] regulations. Should further artifacts be needed when considering other PIL sources, additional artifacts may be added without the need to change existing artifacts, the existing Brussels I activity diagram, or the existing decision support system for Brussels I. Extension, thus, at all levels is possible and even foreseen. Furthermore, the section proves for the case of the Swiss national PIL that the PIL modeling method may be successfully applied to other PIL sources. The same holds true for an implementation of the respective decision support system as the implementation method is not specific to a single PIL, but it considers generally applicable guidelines to implement an activity diagram as a rule-based system.

- B2C and B2B support: The case study conducted considers a B2B contractual relation. All further contributions of this section consider B2C and B2B relations. 
For instance, the information model includes a Brussels-I-specific information artifact holding information about whether a service customer is a consumer (B2C). Similarly, the activity diagram modeled for Brussels I and the according decision support system implemented differentiate B2C and B2B relations. In other PILs, this differentiation might not be relevant. Nonetheless, the information model, the PIL modeling method, and the decision support system implementation provide full support for both.

- Scope of international service contracts: The information model, the PIL modeling method, and the implementation method consider provisions of PIL relevant to international, commercial, and electronic provisioning of services exclusively. A wider focus including so far not envisaged service contracts of similar types may be accommodated at a later stage. The information model, the modeling method, and the implementation method support extensions beyond the scope adopted here.

- Scalability by means of complexity reduction: All contributions have revealed a considerable amount of complexity faced. In particular, the PIL modeling method is affected by complexity and scalability issues. Scalability with respect to a wider geographic, electronic business scheme, and service contract type coverage has been achieved mainly by means of complex reduction through abstraction. Consequently, the PIL modeling method focuses on standard cases. It emphasizes legal compliance and, thus, reliable recommendations produced for frequent and likely contractual relations. On the other hand, it abstracts exceptions and reservations. This decision reflects a trade-off between scalability and specifics. As the detailed inclusion and exclusion criteria for modeling a PIL source, however, are fully documented, any limitation in specifics is made transparent and comprehensible.

In summary, the qualitative analysis of those objectives raised reveals that all objectives have been met successfully. This means that this section provides sufficient support for automation and that it is extensible with respect to a wider geographic, business scheme, and service contract type scope. Extensibility and complexity reduction through abstraction contribute equally to achieve scalability in future work.

\subsection{Future Work and Complexity Mitigation Strategies}

The overall three-step approach as shown in Figure 1 has been developed according to procedures applicable to international contract claims. In this context, the contributions of this section determine major achievements in terms of a common basis for a PIL-specific, successful modeling, implementation, and output generation. On the other hand, wider extension in PIL coverage, supposition of potentially connected jurisdictions, and integration of different jurisdiction/applicable law recommendations have been identified as fields of interest for future work.

While the first may be achieved by making use of the modeling and implementation method as well as by the information model developed, supposition and integration are considerably more challenging, since both bear a high level of complexity and uncertainty. When aiming at a comprehensive, potentially even productive solution, however, the complete set of supposition (step 1 in Figure 1), PIL modeling, implementation, and output production (step 2), as well as integration of recommendations (step 3 ) has to be endorsed. 
In general, the way complexity was addressed in developing the modeling method, the information model, and in the implementation method reflects a "divide-and-conquer" approach. In modeling, the overall procedure was split into distinct steps for which each either guidelines or criteria could be determined. For instance, law selection was split into a pre-selection and detailed in-/exclusion sub-procedure so that complexity was better handled.

In the information model, the starting point was found in an existing SLM model which was extended step-by-step. Again, this happened in order to accomplish a complex procedure. In the implementation, finally, a multi-step procedure focusing on different in- and output variables and predicates implementing partial paths (instead of complete paths) was adopted. The latter facilitates a partial debugging — reducing complexity considerably. These complexity issues lead to the question of how to mitigate such challenges. Three basic directions have been identified as follows:

- Status quo: One way to handle complexity is to not do anything fundamental about it, but to cope with it as good as it gets. Coping means to, e.g., extend both, modeling method and PIL coverage range, possibly with the help of jurists in order to lower potential for misinterpretation. In fact, this strategy is perceived as a pragmatic albeit inefficient and probably only symptomatic approach. Given the fact that territoriality and the respective political implications that come with it are not expected to diminish any time soon, a status quo approach constitutes a realistic option.

- Arbitration: There are alternatives to judicial arbitration. Arbitration is a possible approach to so-called alternative dispute resolution. While alternative dispute resolution shows typically advantages in terms of flexibility and choice over judicial jurisdiction, it may as well turn out as complex as PIL, and enforcement might be a real problem in some cases. In conclusion, arbitration (and other alternative means) is difficult to assess with respect to trade-offs.

- PIL for international service business: The Internet is one of the few truly global infrastructures. Electronic business in the Internet is happening now, and so are international service contracts concluded every day. The existence of a harmonized, widely accepted PIL specific to international service contracts in the Internet would mark a corner stone towards making contracts in the Internet less of a "secondclass" type of contract. Harmonization in PIL is perceived as the only way to address issues with the current approach at the root and in a sustainable manner. Therefore, it must be envisaged as a long-term objective.

\section{Conclusions}

This section has addressed an important problem in contract formation support, especially the automated determination of recommendable jurisdictions and/or applicable laws for an international service contract. Accordingly, the decision support system developed fosters transparency and trust in international electronic business. Due to the determination of jurisdiction and applicable law, the minimization of risks between service provider and service customer has been achieved. Thus, this section's major contribution to SLM and contract management tasks determines an easy-to-use and applicable 
functionality, which can be embedded into SLA management systems due to the availability of contract parameters and their values. Therefore, the practical considerations of such an approach for service providers and service customers are of high importance: (a) they are able to reduce their risks in contract formation and (b) new legislations and laws can be modeled according to the methodology developed and integrated into the existing implementation prototype.

Where minds of service providers, service customers, and policy makers might meet in the long run, is in an internationally harmonized PIL for commercially provided electronic services in the Internet. Such legislation, if drafted in consideration of the respective technical and legal requirements, may overcome those challenges raised by today's territorial approach to Internet jurisdiction. But it is safe to assume that any move in this direction will take time. Nonetheless, it is perceived the only way to essentially and fundamentally foster legal certainty in electronic business in the Internet. This conclusion is irrespective of the decision support system designed and implemented within the scope of this section. It would be of help in modeling and implementing decision support for both contract parties also if there was only a single PIL of relevance. The United Nations Convention on Contracts for the International Sale of Goods (CISG) [17] proves that such an undertaking resulting in internationally harmonized law is feasible, in principle.

Acknowledgment. The authors would like to thank Stefan Bechtold, Thomas Schaaf, and Marinos Charalambides for their valuable input, comments, and feedback.

Open Access. This article is distributed under the terms of the Creative Commons Attribution Noncommercial License which permits any noncommercial use, distribution, and reproduction in any medium, provided the original author(s) and source are credited.

\section{References}

1. van Lith, H.: International Jurisdiction and Commercial Litigation. Uniform Rules for Contract Disputes. Asser Press (July 2009)

2. Kroes, Q.R.: E-business Law of the European Union. Kluwer Law International (2003)

3. Patrikios, A.: Resolution of Cross-border E-business Disputes by Arbitration Tribunals on the Basis of Transnational Substantive Rules of Law and E-business Usages: The Emergence of the Lex Informatica. University of Toledo Law Review 38(1), 271-306 (2006)

4. Geist, M.A.: Is There a There There? Towards Greater Certainty for Internet Jurisdiction. Berkeley Technology Law Journal, 1-63 (Fall 2001)

5. Wang, F.F.: Internet Jurisdiction and Choice of Law: Legal Practices in the EU, US and China. Cambridge University Press (2010)

6. Svantesson, D.J.B.: Private International Law and the Internet. Kluwer Law International (February 7, 2007)

7. Waldburger M., Macri A., Stiller B.: Service Provider Market Activities Constituting Jurisdiction for International Service Contracts-A Structuring Approach and Techno-legal Implications. In: 21st European Regional ITS Conference (ITS 2010), Copenhagen, Denmark, pp. 1-22 (September 2010)

\footnotetext{
${ }^{2}$ For international sales of material goods, not for electronic services.
} 
8. Waldburger, M., Charalambides, M., Schaaf, T., Stiller, B.: Automated Determination of Jurisdiction and Applicable Law for International Service Contracts: Modeling Method, Information Model, and Implementation. In: 18th Biennial and Silver Anniversary International Telecommunications Society Conference (ITS 2010), Tokyo, Japan, pp. 1-31 (June 2010)

9. Waldburger, M., Stiller, B.: Automated Contract Formation for Electronic Value-added Services in the Internet-The Case of Bandwidth-on-Demand Contracts in Europe. In: 37th Research Conference on Communication, Information and Internet Policy (TPRC 2009), Arlington (VA), USA, pp. 1-30 (September 2009)

10. Schaaf, T.: IT-gestütztes Service-Level-Management: Anforderungen und Spezifikation einer Managementarchitektur. PhD thesis, LMU München, Fakultät für Mathematik, Informatik und Statistik, Munich, Germany (November 2008)

11. Council of the European Union: Council Regulation (EC) No 44/2001 of 22 December 2000 on Jurisdiction and the Recognition and Enforcement of Judgments in Civil and Commercial Matters. Official Journal of the European Communities L12, 1-23 (January 2001)

12. Bundesversammlung der Schweizerischen Eidgenossenschaft: Bundesgesetz vom 30. März 1911 betreffend die Ergänzung des Schweizerischen Zivilgesetzbuches (Fünfter Teil: Obligationenrecht), SR 220 (March 1911) (in German)

13. Verizon Business: Ethernet Virtual Private Line (EVPL) (May 2010)

14. Hevner, A.R., March, S.T., Park, J., Ram, S.: Design Science in Information Systems Research. MIS Quarterly 28(1), 75-105 (2004)

15. Frank U.: Towards a Pluralistic Conception of Research Methods in Information Systems Research. ICB-Research Report No. 7, Universität Duisburg-Essen, Essen, Germany (December 2006)

16. European Parliament and the Council of the European Union: Regulation (EC) No 593/2008 of the European Parliament and of the Council of 17 June 2008 on the Law Applicable to Contractual Obligations (Rome I). Official Journal of the European Union, L177, 6-16 (July 2008)

17. United Nations Commission on International Trade Law (UNCITRAL): United Nations Convention on Contracts for the International Sale of Goods (CISG). Convention (April 1980) 